\title{
UMA LEITURA SOCIOCULTURAL DO FUTEBOL BRASILEIRO
}

por Luís Otávio Teles Assumpção*

PERDIGÃO, Paulo. Anatomia de uma derrota. São Paulo: L\&PM, 1986.

Apenas três pessoas, com um único gesto, calaram o Maracanã com 200.000 pessoas: Frank Sinatra, o papa João Paulo II e eu.

(Alcides E. Gigghia)

O objetivo de Anatomia de uma derrota foi analisar o impacto social, cultural e simbólico da derrota da seleção brasileira de futebol para a seleção uruguaia na partida final da Copa do Mundo de 1950, realizada no Brasil. A obra interesssou-me pela originalidade da abordagem, pela profundidade analítica, pelas reflexões teóricoconceituais, pelo método de coleta de dados e pela significativa contribuição para a produção de outros trabalhos na mesma linha de reflexão.

Segundo Perdigão, essa derrota teve, para os brasileiros, uma importância

infinitamente maior do que o peso da correspondente vitória para os uruguaios. O 16 de julho de 1950 provocou uma comoção nacional poucas vezes verificada na vida contemporânea do país, comparável à do suicídio de Getúlio Vargas e à agonia de Tancredo Neves, iniciada no dia de sua posse. (p. 35).

Doutor em Sociologia pela Universidade de Brasília; professor-orientador de Sociologia do Esporte nos cursos de mestrado e doutorado em Educação Física da Universidade Católica de Brasília. E-mail: luiso@pos.ucb.br 
$\mathrm{O}$ autor assistiu àquele jogo. Em 1950, aos 11 anos de idade, esteve, naquele dia, no estádio do Maracanã e relatou sua experiência:

Retive comigo o final da partida, a saída do Maracanã - a multidão descendo conosco as rampas do estádio, arrastando os pés, em silêncio realmente assustador. "Será possível, papai?", foi a única coisa que me lembro de ter dito, logo após o gol de Ghiggia, tão surpreso quanto todos. [...] Como todos os que participaram do evento, inclusive os jogadores, eu não sabia que estava vivendo um momento histórico. (p. 20).

\section{O gol de Ghiggia}

Ghiggia é o nome do jogador que fez o segundo gol uruguaio e deu o título de campeão mundial de futebol ao seu país. Esse gol ficaria na memória nacional como o estigma da tragédia de 50.

Nunca na história do futebol mundial, um único lance acarretou tantas discussões, tantas análises, tantas evocações, talvez porque nenhum, como este, tenha transcendido sua simples condição de fato esportivo para alçar-se às dimensões de drama e mitologia, para converter-se em momento histórico da vida de uma nação. (p. 142).

O gol silenciou todo o estádio:

Embora isto pareça incomum, foi a primeira vez em minha vida que senti algo que não era ruído. Senti o silêncio. Parecia que tudo havia terminado. (Schiaffino, jogador uruguaio - p. 142).

Quando me levantei o Maracanã estava mudo. No centro do campo os uruguaios se beijavam. (Barbosa, goleiro brasileiro - p. 142).

Ghiggia e Schiaffino muitas vezes disseram que "não sabiam" que aquilo que estavam fazendo - "duas simples bolas atiradas a gol” - passaria à História como um capítulo de nossa saga mitológica (p. 35). 
$\mathrm{O}$ autor escreve ter o fato sido "testemunhado por apenas 200.000 pessoas", e, provavelmente, quase todas já desaparecidas. Perdigão diz "apenas" por não haver transmissões televisivas na época.

Ouviu-se falar disso e daquilo, teria acontecido isso ou aquilo -, de tal modo que, em determinado momento, já não seria mais possível saber o que de fato sucedeu no Maracanã naquele dia e o que foi apenas criado e estabelecido como verdadeiro pela imaginação de muitos. (p. 32-33).

Perdigão relata comentários de ex-jogadores:

Eu também, com apenas 10 anos, participei daquela imensa tristeza [...]. Esse 16 de julho eu não esqueço mais. Foi uma tristeza tão grande, tão profunda, que parecia ser o final de uma guerra, com o Brasil perdedor e muita gente morta. (Pelé - p. 37).

Tragédia de 50 a gente não esquece. Passam vinte, trinta anos, e aquilo tudo fica na nossa memória, como uma mancha. (Bigode, lateral-esquerdo, que jogou naquele dia - p. 37).

Ainda hoje os pais me param na rua e dizem a seus filhos: "Este é o Zizinho, que jogou a Copa de 50". Joguei 19 anos, tenho alguns títulos, e sou lembrado, como os demais jogadores daquela campanha, como um perdedor. (Zizinho, um dos principais jogadores brasileiros daquela Copa - p. 37).

Segundo Perdigão, o Brasil havia preparado tudo para vencer - obteve a sede, construiu o maior estádio do mundo, fez uma campanha brilhante, com vitórias esmagadoras, como $6 \mathrm{X} 1$ contra os espanhóis e 7 X 1 contra os suecos. Ninguém duvidava que o Brasil sairia vitorioso. Sobretudo porque, na derradeira partida, iria defrontar-se com o Uruguai, e os uruguaios haviam suado a camisa para passar sem derrotas pelas seleções que o Brasil goleara com incrível facilidade. No entanto, o Brasil perdeu e Perdigão relata palavras do jornalista austríaco Willy Meisl:

$\mathrm{Eu}$, que fora ver uma equipe brilhante sagrar-se campeã, testemunhei o drama de um país inteiro (...). A multidão deixou o estádio em 
silêncio: um silêncio de 200.000 bocas (...). Poucos exemplos se pode achar no Brasil de tão vasta e dolorosa experiência do fracasso. (p. 38).

A manchete do Jornal do Brasil foi: "A maior e mais dramática surpresa que já se abateu sobre o futebol brasileiro".

\section{Contexto social}

$\mathrm{O}$ autor analisou o contexto social brasileiro para melhor entender o impacto da derrota. A década de 50 é uma das mais importantes de toda a história brasileira. Representa a superação do passado colonial e o alvorecer de um mundo urbano-industrial: “ $\mathrm{O}$ Brasil era um país sem glória, saído de uma ditadura, no marasmo do governo Dutra e antes do impacto da volta de Vargas ao poder e da euforia desenvolvimentista de JK" (p. 39).

Perdigão lembra as palavras de Roberto DaMatta sobre a derrota de 50 que, para este, teria sido, talvez, a maior tragédia da história contemporânea do Brasil: "primeiro, porque implicou uma coletividade e trouxe uma visão solidária de perda de uma oportunidade histórica. Segundo, porque ela ocorreu no início de uma década na qual o Brasil buscava marcar o seu lugar como nação que tinha um grande destino a cumprir" (p. 39).

Nesse contexto, a vitória brasileira cumpriria importante função simbólica. Uma Copa do Mundo pode ser analisada como um imenso cartão postal: apresentava-se uma bela oportunidade para o Brasil mostrar ao mundo que poderia competir com os países mais desenvolvidos e vencê-los. Não por acaso, a voz do prefeito do Rio de Janeiro, Ângelo Mendes de Morais, ecou por todo o estádio "falando que já estava na hora de mostrarmos ao mundo que não éramos bugres e que deveríamos vencer como cavalheiros" (p. 28). 


\section{Uma leitura filosófica}

Paulo Perdigão possui formação em Filosofia, tendo sido, inclusive, o tradutor para o português da obra O Ser e o Nada, de Jean-Paul Sartre. Sua formação lhe permitiu elaborar uma leitura original sobre esse jogo de futebol.

Simbolicamente, a perda do título representou a própria morte, “a porta fechada atrás da qual nada existe" (p. 39). A derrota de 50, para os brasileiros, "traduziu metaforicamente a luta tenaz e inglória do homem contra a morte: nossa vida vence algumas batalhas para perder justamente a última e decisiva" (p. 39-40).

Lembra Perdigão que a derrota de 1950 coincidiu com a difusão, na Europa, do pensamento existencialista, "amadurecido durante os horrores da guerra e que, nas palavras de Camus, reafirmava o homem como 'um estranho em um mundo absurdo, no qual só conhece a inevitabilidade do sofrimento e da morte", ( $\mathrm{p}$. 40). A perda da Copa do Mundo, in extremis,

significou a experiência da morte do outro, a morte repentina e inesperada de um ente querido, para a qual ninguém estava preparado e com a qual ninguém pode se consolar. A morte que Sartre designa como "puro fato, radicalmente absurdo, que está fora dos meus projetos, que eu não posso esperar e que me vem de fora, por acaso”. (p. 40).

\section{Rivalidade histórica}

Perdigão levanta a hipótese de o Uruguai, "um país tão pequeno, com menos heróis e glórias que o Brasil, encontrar no futebol uma grande oportunidade de afirmação nacional". Daí o surgimento da mística da Celeste Olímpica: “os jogadores do Uruguai trazem no peito o azul heróico de tantas glórias. Segundo essa mística, esses jogadores crescem tanto, envergando a celeste, 
que se diria que sua camisa tem tanto valor quanto tinha para Davi sua funda contra Golias" (p.66). Recolhe depoimentos:

Somos um povo muito atrevido. O Uruguai se sente sempre muito 'ele'. Não concebem que se adiantem a ele por qualquer maneira. Somos um paisinho, mas falamos aos demais com muita firmeza. Somos audazes - essa é a nossa mística [...]. Cada um que veste a camiseta celeste a põe como uma coisa sagrada, como um brasão que nos permite, às vezes, conseguir triunfos que nos parecem vedados. (goleiro Máspoli - p. 66).

Tínhamos que respeitar e defender uma herança fabulosa. (capitão Obdúlio Varela - p. 66).

É a força da memória coletiva, o "passado inarredável, completo, no presente", como alhures já nos ensinou Câmara Cascudo.

\section{O triunfo por antecipação}

Associada a esta forte consciência coletiva, os uruguaios certamente desgostaram das manchetes dos jornais do dia da final da Copa do Mundo:

Gazeta Esportiva (15 de julho de 1950): "Venceremos o Uruguai”.

Diário Carioca (15 de julho de 1950): “O Uruguai também será goleado".

Il Messagero, de Roma (divulgada pelo Diário de Notícias, 16 de julho de 1950): "Não pode mais subsistir qualquer dúvida a respeito da vitória final do torneio".

Escreve Perdigão que não havia jornal ou revista no mundo inteiro que não tivesse já pronto o título "Brasil, campeão do mundo" e relata comentário do jornalista Geraldo Romualdo:

O Manuel Caballero - cônsul do Uruguai - comprou vinte e tantos jornais, foi ao Hotel Paissandu, esperou que os jogadores se 
sentassem à mesa para seu último almoço antes do jogo e disse: "Meus pêsames, os senhores já estão vencidos". Houve então um jogador, se não me engano o Tejera, que era um leão, um sujeito meio grosso, que deu um soco na parede e disse: "Não, não! Não são campeões! Vamos ver quem será o campeão!” (p. 68).

Outra história diz ter Obdúlio Varela comprado os jornais e com as páginas da manchete forrou o banheiro reservado aos jogadores no hotel. Vários jogadores urinaram sobre a fotografia da seleção brasileira. "Além do banheiro, as páginas estavam espalhadas por todos os cantos da concentração. El grán capitán Obdúlio Varela as havia distribuído com raiva, e em silêncio" (p. 68).

Perdigão resgata depoimento de Zizinho:

Acho que essa é a maior arma que se pode dar ao adversário: dizer uma coisa dessas, na véspera de uma partida (...) Acho que o jogador adversário vai se multiplicar para provar o contrário. E essas armas todas nós demos ao Uruguai. (p. 68).

\section{"Nunca mais... nunca mais..."}

Perdigão se vale das reflexões de Arno Vogel para melhor compreender o sentimento de imensa tristeza que se apoderou dos brasileiros:

Foi como se o Brasil tivesse perdido a mãe-pátria [...] o estado de desolação tinha algo de delírio, mas delírio ordenado, uma espécie de transe. Tudo parecia seguir um plano. Era um ritual - o ritual do luto [...]. Na hora da tristeza todo mundo se uniu. Todo mundo era brasileiro. Então, foi o Brasil que foi derrotado. [...] Foi a coisa mais triste do mundo a que se assistiu. No final do jogo, um sujeito ainda estava com a bandeira do Brasil no alto. Aquela bandeira veio pelo Maracanã, pela rua São Francisco Xavier, e eu atrás dela. E o rapaz que levava a bandeira chorava também. Foi o nosso fracasso, e a nossa vergonha. (Vogel, 1982, p. 90).

Vogel afirma (1982, p. 113) que esse sentimento geral de extrema humilhação, de perda da honra e 'morte social', coexiste com a impressão de que 
a derrota, ocorrida em casa, nos nossos próprios domínios - "uma forma mais definitiva de perder" -, representou o funeral da nação. Os brasileiros foram para casa, em silêncio. Ou seja: abandonaram a rua - o mundo dos homens, onde se luta pela vida - e se exilaram em casa - que é o "asilo inviolável do indivíduo", lugar "onde o luto, a dor e a vergonha podem ser escondidos". O oposto da vitória, quando todos vão para a rua festejar. Aqui, cada um só pensava em se isolar do mundo. Por isto não houve desordens, nem brigas na cidade.

\section{A herança racista}

Uma busca incansável de explicações e responsabilidades para aceitar a derrota varreu o país inteiro. Segundo Perdigão, "reacendeu-se uma questão derivada do tempo do Estado Novo: a deficiência da 'raça brasileira', causa da nossa inferioridade como nação" (p. 171). A perda para o Uruguai funcionava como uma "metáfora das derrotas brasileiras" (p. 39). Se para aqueles que jogaram a Copa do Mundo, a derrota era a amarga despedida, para o restante dos brasileiros,

era a honra ultrajada, a humilhante retirada para o lugar insignificante de onde nunca deveriam ter saído, segundo o velho complexo de uma sociedade subdesenvolvida que se considera "racialmente impura". (p. 39).

Não por acaso, boa parte da crítica atribuiu a responsabilidade da derrota aos negros da seleção brasileira - o goleiro Barbosa e os jogadores Juvenal e Bigode - "assim, embora tivesse mais categoria, o Brasil não tinha garra e, nessa ótica, só mesmo nossa 'inferioridade racial' parecia justificar a perda do campeonato dentro da própria trincheira" (p. 171).

A derrocada foi atribuída ao atraso do país e "reavivou um tradicional pessimismo na ideologia nacional: éramos inferiores por um destino ingrato" (p. 39). 
Perdigão lembra que o preto Bigode e o mulato Juvenal, sem contar o goleiro Barbosa, também preto, foram os principais acusados e transcreve as palavras do jornalista Mário Filho: "a prova da derrota de 50 estaria naqueles bodes expiatórios, todos de cor: Barbosa, Juvenal e Bigode" (p. 171).

\section{Referência bibliográfica}

VOGEL, Arno. O momento feliz: reflexões sobre o futebol e o ethos nacional. In: DaMATTA, Roberto et al. Universo do futebol. Rio de Janeiro: Pinakotheke, 1982. 